\title{
A ATUALIDADE DO DEBATE SOBRE TRABALHO E DESENVOLVIMENTO
}

\author{
INTRODUÇÃO
}

\author{
José Ricardo Ramalho* \\ Roberto Véras de Oliveira ${ }^{* *}$
}

Uma das questões mais importantes do debate contemporâneo sobre o trabalho tem sido a demanda por explicações teóricas e por pesquisas empíricas mais consistentes acerca de sua manifestação em países com situações permanentes de pobreza e deficit de cidadania. Discutir o trabalho nessa perspectiva requer uma ampliação dos horizontes de investigação, uma revisão de conceitos clássicos e uma abertura de novas frentes de reflexão. Foi com esta intenção que reunimos o conjunto de artigos desse Dossiê, articulando a problemática atual do trabalho com a retomada do tema do desenvolvimento.

A discussão sobre desenvolvimento ganhou centralidade nas Ciências Sociais brasileiras e lati-

* Doutor em Ciências Sociais (Ciência Política) e pósdoutorados na Universidade de Londres (UK) e na Universidade de Manchester (UK). Professor titular do Departamento de Sociologia e do Programa de Pós-Graduação em Sociologia e Antropologia da Universidade Federal do Rio de Janeiro (UFRJ).

Largo de São Francisco 1, sala 418, Centro. Cep: 20051070 -Rio de Janeiro-RJ-Brasil. josericardoramalho@gmail.com

* * Doutor em Sociologia. Professor do Departamento de Ciências Sociais da Universidade Federal da Paraíba (UFPB) e membro do Programa de Pós-Graduaçãa em Sociologia da UFPB (PPGS) e do Programa de Pós-Graduação em Ciências Sociais da Universidade Federal de Campina Grande (PPGCS/UFCG).roberto.veras.2002@gmail.com no-americanas desde a metade do século XX. Suscitou diversas interpretações sobre as dinâmicas econômicas e sociais alteradas pela ação do Estado em uma perspectiva nacional-desenvolvimentista, que se voltaram para a "modernização" com ênfase na industrialização, para projetos de infraestrutura e para a constituição de um sistema de regulação jurídica face a um mercado de trabalho pouco estruturado e pouco adaptado ao emprego industrial.

Tida como uma "década perdida", quando analisada pelo ângulo estrito da economia, a década de 1980, em perspectiva política, esteve marcada por uma maior participação de setores populares e de trabalhadores no debate sobre democracia, na luta por direitos, quando, por essa via, se "constituiu a base fundamental para a emergência de uma nova noção de cidadania” (Dagnino, 1994, p. 104).

Na virada dos anos 1990, no entanto, os impactos sociais da globalização econômica e das políticas neoliberais se fizeram sentir nas sociedades latino-americanas. Observou-se "uma desconcentração do poder do Estado nacional, reorientado por reformas em favor do mercado". Tal perspectiva aprofundou a ruptura do pacto nacional- 
desenvolvimentista (entre Estado, elites empresariais e trabalhadores assalariados urbanos), que tinha vigorado até os anos 1970 (Ivo, 2012, p. 198). Se, nos anos 1980, tendo o caso brasileiro como emblema, a questão social foi ressignificada na perspectiva dos direitos de cidadania, na década seguinte o que se viu foi um movimento de “refilantropização da pobreza” (Yazbek, 1995). A dívida social cresceu com o desemprego elevado, o aumento da informalidade e da vulnerabilidade das mulheres e dos jovens trabalhadores, o esvaziamento das negociações coletivas e das ações sindicais, a "precarização" das relações de trabalho (DIEESE, 2001).

As dinâmicas socioeconômicas e políticas se alteraram ao longo da década de 2000. Segundo Boschi e Gaitán (2008, p. 305 e 306), ocorre, nesse período, "o enfraquecimento da hegemonia neoclássica e uma retomada de trajetórias de intervenção estatal na economia, observando-se uma diversidade de caminhos neodesenvolvimentistas". O principal desafio dos países latino-americanos passou a ser o de "quebrar um círculo vicioso e reverter as trajetórias prévias sinalizadas pelo subdesenvolvimento, pelo atraso relativo e pela desigualdade na distribuição de renda” (Idem, p. 305).

Na retomada do debate sobre o tema do desenvolvimento, a dimensão social tem sido mais enfaticamente reivindicada. É o caso de Kerstenetsky (2011), que propõe uma articulação entre as propostas de desenvolvimento e o estado do bem-estar social, de modo a compatibilizar crescimento econômico e equidade social. Para Ivo (2012, p. 206), a relevância social da agenda de desenvolvimento deve ser considerada para além das políticas de transferência de renda, visto que o enfrentamento das desigualdades sociais não pode prescindir de "políticas vigorosas de proteção e integração social", as quais "dependem das condições estruturais da distribuição, da qualidade das políticas públicas e da qualidade de inserção dos indivíduos na esfera do trabalho...”.

A problemática atual do trabalho, referida à retomada de um discurso desenvolvimentista, ganha particular relevância quando associada, seja às diversas experiências de participação política e institucional dos trabalhadores e dos movimentos sociais nas últimas décadas, seja ao modo como políticas de desenvolvimento lidam com estratégias empresariais de flexibilização e precarização das relações de trabalho, de desrespeito à legislação protetiva do trabalho, de descaso com as consequências ambientais e seu impacto sobre diferentes setores da população.

Os estudos sobre o trabalho em um cenário de globalização, em contextos de países periféricos, trouxeram desafios de interpretação, tendo em vista substantivas diferenças no perfil do mercado de trabalho e nas estratégias empresariais com relação às condições de emprego e à reestruturação das atividades produtivas. As mudanças no mundo do trabalho, originadas nos processos de reestruturação produtiva; a introdução de um padrão flexível na organização dos processos de trabalho, como forma de lidar com as novas tecnologias e, ao mesmo tempo, estabelecer novos parâmetros para as relações salariais; a capacidade de deslocamento geográfico das empresas e sua estruturação em rede, como forma de obter vantagens comparativas; todos esses elementos aparecem de forma diferenciada na realidade econômica e social dos países da America Latina (Ramalho, 2000). Na tradição crítica do pensamento sociológico brasileiro e latino-americano, os destacados aspectos da flexibilização foram objeto de questionamento e valorizou-se uma linha de interpretação que mostrava as consequências sociais desse processo, a "precarização" do trabalho e seus efeitos sobre a organização da sociedade. Tal perspectiva, ao mesmo tempo em que ressalta a importância de identificar as situações de "precarização social", demonstra as contradições entre os processos de modernização percebidos como progresso e processos de regressão social cada vez mais visíveis.

A proximidade política da reestruturação das empresas e da expansão das redes globais de produção com os modelos de política econômica de perfil neoliberal tiveram um impacto imediato nas dinâmicas do trabalho no Brasil. As pesquisas realizadas sobre o período que se inicia nos anos 
1990 identificaram efeitos sociais que fragilizaram trabalhadores e desempregados. A flexibilização das empresas através da "terceirização", por exemplo, reduziu direitos, rebaixou salários e tornou instáveis os empregos. O alto grau de informalização do mercado de trabalho e a presença da exclusão e da pobreza permaneceram como traços marcantes. Esse perfil do trabalho se manteve também nos anos 2000, quando uma maior ênfase no crescimento econômico se consolidou no cenário político. Tal retomada resultou em um maior incremento das políticas sociais, com mudanças relevantes nos indicadores sociais e do trabalho, sem, no entanto, trazer alterações de tipo mais estruturais (Pochmann, 2012).

Toda uma linhagem especialmente delimitada pela noção de "economia solidária" se estabeleceu, enquanto ação coletiva e política pública, recolocando em cena as experiências associativas e solidárias nos campos da produção, comercialização, crédito e trabalho. Por outro lado, o novo contexto de desenvolvimento tem exigido uma necessária ligação da temática do trabalho com os contextos específicos dos "territórios produtivos", as estratégias de investimento das cadeias produtivas e as políticas de desenvolvimento local e regional.

Por tudo isso se justifica um olhar direcionado para as implicações recíprocas entre a nova agenda de desenvolvimento e as novas dinâmicas do trabalho. De um lado, a necessidade de investigar as consequências das novas políticas de desenvolvimento para as relações de trabalho. Em que medida e de que modo as pressões mundiais pela flexibilização e precarização das relações de trabalho se aplicam ao Brasil e a outros países da América Latina? De outro lado, até que ponto os movimentos sociais, o sindicalismo e outras formas de ação coletiva, referidas ao mundo do trabalho e às questões sociais e ambientais, vêm conseguindo influenciar os padrões de desenvolvimento que se estabelecem?

A proposta deste Dossiê não é o de cobrir todo esse conjunto de considerações e questões, mas de demonstrar, através dos artigos escritos e diferentes abordagens, um campo possível de arti- culação entre as temáticas do trabalho e do desenvolvimento, sinalizando a sua complexidade para os estudos sociológicos.

Começamos com um estudo sobre como uma das expressões de maior destaque do sindicalismo brasileiro vem tematizando a questão do desenvolvimento, justo na região de maior tradição industrial do país. No texto "Sindicato, desenvolvimento e trabalho: crise econômica e ação política no ABC”, José Ricardo Ramalho e Iram Jácome Rodrigues, a partir da atuação do sindicato dos metalúrgicos do $\mathrm{ABC}$ paulista nas últimas duas décadas, especialmente durante a crise de 2008, discutem e problematizam o envolvimento direto de entidades de representação de trabalhadores em espaços não-fabris, no debate sobre estratégias de desenvolvimento e seus desdobramentos em contextos regionais. O texto revela as diferentes inserções e perspectivas dos atores sociais locais, regionais e nacionais na busca de alternativas para a crise econômica mundial e demonstra como, através de um evento público, sem apagar as contradições e os conflitos de uma realidade social marcada pela assimetria de posições na estrutura social, o sindicato exerceu seu poder de mobilização e criou alternativas concretas para enfrentar o desemprego e as ameaças de uma conjuntura hostil aos trabalhadores.

Na sequência, em contraste com o caso anterior, trazemos uma abordagem sobre os conflitos do trabalho e a ação sindical em um território na periferia do país, onde vem ocorrendo um boom de industrialização, induzido por políticas desenvolvimentistas. No texto "Suape em construção, peões em luta: o novo desenvolvimento e os conflitos do trabalho", Roberto Véras de Oliveira analisa a emergência de uma nova agenda de desenvolvimento no Brasil através da ótica do trabalho e de seus conflitos. Tomando como exemplo a construção de empreendimentos industriais no Complexo Industrial Portuário de Suape, em Pernambuco, e enfocando, principalmente, as revoltas e greves de trabalhadores envolvidos nas obras de construção das principais plantas industriais, o autor mostra como tais conflitos permitem apreender os processos desencadeados (conflitos, 
mediações e negociações) e o que está em disputa (com as demandas dos trabalhadores e os discursos e práticas governamentais, empresariais e sindicais). A questão que se coloca ao final é se essas mobilizações, além de ganhos imediatos para os trabalhadores, são capazes de lhes dar reconhecimento como legítimos portadores de demandas sociais. E se tais demandas não colocam em xeque os termos do novo discurso desenvolvimentista.

Um elemento em evidência nesse novo arranjo discursivo se refere à sua associação com a questão ambiental. Neste particular, um dos aspectos mais controversos diz respeito ao modo como se articulam os temas da "energia limpa" e da produção de etanol. No texto "A imagem do etanol como "desenvolvimento sustentável" e a (nova) morfologia do trabalho", Maria Aparecida Moraes e Silva et al analisam as relações e condições de trabalho nos canaviais paulistas e alagoanos, resultantes de um processo de reconfiguração do trabalho pela intensificação da mecanização do corte de cana. A proposta é mostrar, criticamente, como a ideologia desenvolvimentista relacionada a essas mudanças, introduzidas pelas empresas sucroalcooleiras e estimuladas pelo Estado, tem resultado em uma intensificação da exploração da força de trabalho no quadro de uma (nova) morfologia que combina tecnologias avançadas com um aumento da desqualificação dos trabalhadores.

Discutir modelos de desenvolvimento implica, também, abordar as mudanças no mercado de trabalho e no modo como se tratam questões como a flexibilização dos empregos e a manutenção de direitos. Em "A retomada do desenvolvimento e a regulação do mercado de trabalho no Brasil", Paulo Baltar e José Dari Krein argumentam que a retomada do crescimento da economia brasileira permite redefinir os termos do debate sobre o trabalho. Sob tal pressuposto, estabelecem uma relação entre a dinâmica do capitalismo contemporâneo e os desafios de uma regulação pública do trabalho. Ressaltam que a crise econômica mundial abre a possibilidade de o Estado ter um papel mais ativo nas políticas de desenvolvimento e alertam, no caso brasileiro, para os desdobramen- tos do aumento do peso da PEA adulta, em relação ao funcionamento do mercado de trabalho. Os autores identificam, nesse contexto, um embate entre os que defendem uma estruturação do mercado de trabalho com implicações na qualidade das relações sociais e os que destacam a necessidade de uma maior flexibilização na contratação, no uso e na remuneração do trabalho. E associam estas diferentes posições ao modelo de desenvolvimento e às políticas públicas do trabalho que o país vem implementando.

O texto seguinte se dedica às possibilidades de uma regulação pública do trabalho, mais especificamente à relação entre o segmento de trabalhadores jovens sem escola e sem trabalho e a reprodução da pobreza. Em "Juventude, trabalho e desenvolvimento: elementos para uma agenda de investigação", Adalberto Cardoso discute a situação dos jovens que não estudam nem trabalham, fenômeno que vem chamando a atenção no contexto pós-crise econômica de 2008, especialmente na Europa. O autor argumenta que, no Brasil, a condição "nem nem" é estrutural, e propõe um modelo analítico de explicação das transformações ocorridas entre 2000 e 2010. Sugere que as mudanças estruturais por que passou o país e as políticas públicas de redução de barreiras ao acesso à escola e ao mercado de trabalho reduziram o impacto das desigualdades regionais e aumentaram o peso da pobreza na explicação da condição "nem nem" dos jovens.

O último texto, de cunho mais teórico, trata da adequação das interpretações sobre as tendências e os sentidos do trabalho na sociedade capitalista contemporânea a partir da especificidade da realidade latino-americana. No artigo "Trabajo no clásico y flexibilidad”, Enrique de la Garza Toledo faz um balanço dessa literatura e atribui destaque a uma dimensão insuficientemente explorada da teoria através do uso do conceito de "trabalho não clássico". No texto, ele relaciona esse tipo de trabalho com as atividades de serviço, que adquirem importância nas economias capitalistas centrais, mas também nas economias menos desenvolvidas. E, ao recapitular a discussão sobre flexibilidade, reivindica a sua ampliação para incluir os traba- 
lhos não-clássicos, em especial a subcontratação. O autor finaliza com a discussão sobre a fragmentação de identidades e a servidão voluntária e seus vínculos com o trabalho não-clássico e sugere atenção à possibilidade de constituição de sujeitos do trabalho mesmo nestas condições.

Ao final, esperamos que as questões apresentadas e discutidas nesse Dossiê tragam novos elementos para o debate sobre a centralidade do trabalho na sociedade contemporânea e para uma reflexão mais aprofundada sobre os diferentes desdobramentos que envolvem os processos de desenvolvimento econômico, com ênfase na necessidade da participação da sociedade e dos trabalhadores na sua formulação e na distribuição dos seus resultados.

Recebido para publicação em 14 de junho de 2013 Aceito em 26 de junho de 2013

\section{REFERÊNCIAS}

BOSCHI, Renato; GAITÁN, Flavio. Intervencionismo estatal e políticas de desenvolvimento na América Latina. Caderno CRH. Salvador: EDUFBA, v. 21, n. 53, p. 305322, Maio/Ago, 2008.

DAGNINO, Evelina. Os movimentos sociais e a emergência de uma nova noção de cidadania. In: DAGNINO, E. (Org.). Anos 90: política e sociedade no Brasil. São Paulo: Brasiliense, p. 103-115. 1994.

DIEESE. A situação do trabalho no Brasil. São Paulo: Dieese, 2001.

IVO, Anete B. L. O paradigma do desenvolvimento: do mito fundador ao novo desenvolvimento. Caderno CRH. Salvador: EDUFBA, v. 25, n. 65, p. 187-210, Maio/Ago. 2012.

KERSTENETZKY, Celia Lessa. Welfare state e desenvolvimento. Dados, Rio de Janeiro, v. 54, n. 1, p. 129-156, 2011.

POCHMANN, Márcio. Nova classe média? O trabalho na base da pirâmide social brasileira. São Paulo: Boitempo, 2012, 128p.

RAMALHO, José Ricardo. Trabalho e sindicato: posições em debate na sociologia hoje. Dados, Rio de Janeiro, v.43, n. 4, p. 761-777, 2000 .

YAZBEK, Maria Carmelita. A política social brasileira nos anos 90: refilantropização da Questão Social. In: Cadernos $A B O N G$, n. 11, 1995.

José Ricardo Ramalho - Doutor em Ciências Sociais (Ciência Política) na Universidade de São Paulo, e pósdoutorados na Universidade de Londres (UK) e na Universidade de Manchester (UK). Professor titular do Departamento de Sociologia e do Programa de Pós-Graduação em Sociologia e Antropologia da Universidade Federal do Rio de Janeiro (UFRJ). Pesquisador do CNPQ. Sua atuação acadêmica está mais voltada para a área da Sociologia do Trabalho e seus principais temas de pesquisa são: relações de trabalho na indústria; sindicato e sindicalismo; reestruturação produtiva e distritos industriais; trabalho, emprego e desenvolvimento econômico regional e local; identidade operária. Autor e coautor de várias publicações em revistas científicas e livros. Entre estes, Estado Patrão e Luta Operária: o caso FNM. Rio de Janeiro, Paz e Terra, 1989; Trabalho e Sindicato em antigos e novos territórios produtivos. São Paulo: Annablume, 2007.

Roberto Véras de Oliveira - Doutor em Sociologia pela Universidade de São Paulo. Professor do Departamento de Ciências Sociais da Universidade Federal da Paraíba (UFPB) e membro do Programa de Pós-Graduação em Sociologia da UFPB (PPGS) e do Programa de Pós-Graduação em Ciências Sociais da Universidade Federal de Campina Grande (PPGCS/UFCG). Pesquisador do CNPQ. Preferencialmente, orienta seus estudos e pesquisas para os campos da Sociologia do Trabalho e da Sociologia Política. Tem concentrado sua atenção (na forma de publicações, orientações e participação em eventos) sobre temas como sindicalismo, relações de trabalho, qualificação profissional, políticas públicas de trabalho, emprego e renda, economia solidária, diálogo social, cidadania, entre outros. É autor e coautor de várias publicações em revistas científicas e livros. Entre estes, Sindicalismo e Democracia no Brasil - do novo sindicalismo ao sindicato cidadão. São Paulo: Annablume, 2011. 
